\title{
Changes in CVD risk factors in the activity counseling trial
}

This article was published in the following Dove Press journal:

International Journal of General Medicine

I 8 January 201 I

Number of times this article has been viewed

\author{
Meghan Baruth' \\ Sara Wilcox' \\ James F Sallis ${ }^{3}$ \\ Abby C King ${ }^{4,5}$ \\ Bess $\mathrm{H}$ Marcus ${ }^{6}$ \\ Steven N Blair ${ }^{1,2}$ \\ 'Department of Exercise Science, \\ ${ }^{2}$ Department of Epidemiology and \\ Biostatistics, Arnold School of Public \\ Health, University of South Carolina, \\ Public Health Research Center, \\ Columbia, SC, USA; ${ }^{3}$ Department \\ of Psychology, San Diego State \\ University, San Diego, CA, USA; \\ ${ }^{4}$ Department of Health Research \\ and Policy, ${ }^{5}$ Stanford Prevention \\ Research Center, Department of \\ Medicine, Stanford University School \\ of Medicine, Stanford, CA, USA; \\ ${ }^{6}$ Behavioral and Social Sciences \\ Section, Brown University Program in \\ Public Health, Providence, RI, USA
}

Correspondence: M Baruth

Department of Exercise Science, Arnold School of Public Health, University of South Carolina, Public Health Research Center, 921 Assembly Street, Columbia,

SC 29208, USA

Tel +l 8037772354

Fax + I 8037770558

Email stritesk@mailbox.sc.edu
Abstract: Primary care facilities may be a natural setting for delivering interventions that focus on behaviors that improve cardiovascular disease (CVD) risk factors. The purpose of this study was to examine the 24-month effects of the Activity Counseling Trial (ACT) on CVD risk factors, to examine whether changes in CVD risk factors differed according to baseline risk factor status, and to examine whether changes in fitness were associated with changes in CVD risk factors. ACT was a 24-month multicenter randomized controlled trial to increase physical activity. Participants were 874 inactive men and women aged 35-74 years. Participants were randomly assigned to one of three arms that varied by level of counseling, intensity, and resource requirements. Because there were no significant differences in change over time between arms on any of the CVD risk factors examined, all arms were combined, and the effects of time, independent of arm, were examined separately for men and women. Time $\times$ Baseline risk factor status interactions examined whether changes in CVD risk factors differed according to baseline risk factor status. Significant improvements in total cholesterol, high-density lipoprotein cholesterol (HDL-C) and low-density lipoprotein cholesterol, the ratio of total cholesterol to HDL-C, and triglycerides were seen in both men and women who had high (or low for HDL-C) baseline levels of risk factors, whereas significant improvements in diastolic blood pressure were seen only in those men with high baseline levels. There were no improvements in any risk factors among participants with normal baseline levels. Changes in fitness were associated with changes in a number of CVD risk factors. However, most relationships disappeared after controlling for changes in body weight. Improvements in lipids from the ACT interventions could reduce the risk of coronary heart disease in people with already high levels of lipids by $16 \%-26 \%$ in men and $11 \%-16 \%$ in women. Interventions that can be implemented in health care settings nationwide and result in meaningful population-wide changes in CVD risk factors are needed. The ACT physical activity interventions produced substantial improvements among men and women with elevated CVD risk factors.

Keywords: primary care counseling, cardiovascular disease risk factors, physical activity, fitness, behavioral intervention

\section{Introduction}

Cardiovascular disease (CVD) accounts for $25 \%$ of all deaths in the US. ${ }^{1}$ Hypertension ${ }^{2}$ and hyperlipidemia ${ }^{3}$ are two established risk factors for CVD. Results from the National Health and Nutrition Examination Survey (NHANES) indicate that among adults aged 20 years and older, $21 \%$ have elevated low-density lipoprotein cholesterol $(\mathrm{LDL}-\mathrm{C})^{4}$ and $29 \%$ have hypertension ( $\left.\geq 140 / 90 \mathrm{~mm} \mathrm{Hg}\right) .{ }^{5}$ Physical activity (PA), a major modifiable risk factor for CVD, is associated with a decreased risk for both hypertension $^{6}$ and deleterious lipid levels. ${ }^{7}$ 
CVD is a serious public health burden in terms of life-years lost, reduced quality of life, and medical costs. ${ }^{8}$ Potentially low-cost interventions that can be successfully implemented population-wide and result in reductions in CVD risk factors should be a public health priority. Numerous behavioral interventions targeting CVD risk factor reduction through PA, diet, weight loss, and/or other lifestyle changes, either as primary or secondary outcomes, have been reported. Most have targeted multiple lifestyle factors including diet and PA, ${ }^{9-25}$ whereas fewer have focused exclusively on PA. ${ }^{26-30}$ Systematic reviews of randomized controlled trials have found that aerobic exercise significantly lowers blood pressure $^{6,31}$ and improves lipids and lipoproteins. ${ }^{32,33}$

Primary care facilities are a natural setting for delivering interventions to improve CVD risk factors. Primary care settings have the potential to reach large numbers of people, as nearly $87 \%$ of US adults see a health care professional at least one time a year, and nearly $25 \%$ have at least four visits a year. ${ }^{34}$ Visits to a primary care facility offer a "teachable moment" in which behavior change can be discussed. Despite the appeal of behavioral interventions in primary care settings, a recent review concluded that lifestyle counseling interventions delivered in these settings have marginal benefit in changing CVD risk factors in low-risk patients. ${ }^{35}$ Of the studies that included PA as a part of the lifestyle intervention in the review, three of six found small but significant benefits for blood pressure, ${ }^{22,24,25}$ and one of four found small but significant benefits for cholesterol. ${ }^{25}$

The Activity Counseling Trial (ACT) was a 2-year multicenter randomized controlled trial delivered in primary care settings that evaluated the effects of three levels of PA counseling on cardiorespiratory fitness (fitness) and PA..$^{36,37}$ Secondary outcomes included the CVD risk factors of resting blood pressure, lipids, and lipoproteins. Primary outcomes have been reported elsewhere. ${ }^{38}$ Briefly, women in the two intervention arms receiving physician advice plus counseling from a health educator had significantly greater improvements in fitness compared with the physician-adviceonly comparison arm at 24 months. Differences in fitness for men did not differ across intervention arms; all three arms improved over the 24-month study period..$^{38}$ The purpose of this paper is to: 1) examine the effects of the ACT interventions on CVD risk factors, ie, systolic blood pressure (SBP) and diastolic blood pressure (DBP), lipoproteins (total cholesterol [TC], high-density lipoprotein cholesterol [HDL-C], LDL-C, the ratio of TC to HDL-C, and triglycerides; 2) examine whether changes in CVD risk factors differed according to baseline risk factor status (high versus normal);
3) examine whether changes in fitness were associated with changes in CVD risk factors; and 4) examine whether changes in weight explained associations between changes in fitness and changes in CVD risk factors.

\section{Methods}

Detailed descriptions of ACT have been published. ${ }^{36-38}$ Participants were recruited over an 18-month period (1995-1997) from 10 primary care facilities, involving 51 physicians, four physician assistants, and one nurse practitioner..$^{38}$ Participants were inactive adults, aged 35-75 years, in stable health, planning and/or scheduled to see their primary care health professional during recruitment, able to read and write in English, independent in their daily living, and able to increase their PA levels. ${ }^{37}$

The primary care facilities used for recruitment were affiliated with three clinical centers: Stanford University, the University of Tennessee, and the Cooper Institute in conjunction with the University of Texas Southwestern Medical Center. The ACT coordinating center was Wake Forest University School of Medicine, and the project office was the National Heart, Lung, and Blood Institute. ${ }^{38}$ The ACT study was approved yearly by each of the institutional review boards from the clinical and coordinating centers.

\section{Intervention}

After baseline assessments, participants were randomly assigned to one of three treatment arms that varied by level of counseling, intensity, and resource requirements: physician/health care provider advice (ie, optimal standard care), assistance, and counseling. ${ }^{36}$ Social cognitive theory $(\mathrm{SCT})^{39}$ and the transtheoretical model (TTM) $)^{40}$ guided the ACT intervention. ${ }^{36}$ With the exception of physician advice, the intervention was delivered by ACT health educators. ${ }^{38}$ All three arms were given the same PA goals, based on the national recommendations of 5 or more days of 30 minutes or more of moderate intensity $\mathrm{PA}^{41}$ or 3 or more days of 30 minutes or more of vigorous intensity PA. ${ }^{42}$

Participants in the standard care or "advice" arm received brief counseling (2-4 minutes) from their primary care provider on the recommended amount of PA and were given standard written materials on PA guidelines from the ACT health educator. ${ }^{36,38}$ Participants in this arm were invited to call the health educator with any questions regarding their PA program (eg, type or amount of PA); however, behavioral counseling was not provided..$^{36,38}$

Participants randomized to the staff assistance intervention or "assistance" arm received the same provider advice and 
educational materials as the advice arm, plus a 30-40 minute counseling session with a health educator and monthly theory-based, behavior change-oriented interactive mailed newsletters. ${ }^{36,38}$ The interactive mail component was intended to increase cognitive and behavioral skills for increasing PA. ${ }^{36,38}$ Each newsletter included a postage-paid mail-back card for reporting weekly PA, current goals, and barriers to PA. After receiving the mail-back card, health educators sent the participants feedback sheets addressing the specific barriers they encountered. ${ }^{36,38}$ Participants in this arm also received an electronic pedometer and calendar to encourage self-monitoring, inexpensive incentives, and brief behavioral counseling from the health educators at each subsequent naturally occurring visit to his or her physician. ${ }^{36,38}$

Participants in the staff-counseling intervention or "counseling" arm received everything the advice and assistance arms received plus health educator-initiated telephone counseling biweekly for the first 6 weeks, then monthly for the remainder of the first year. During the second year, the health educator and participant decided together how frequent the subsequent counseling calls would be. ${ }^{36,38}$ Weekly behavior change classes conducted by the health educators were also offered to participants in this intervention arm. The classes focused primarily on building the cognitive and behavioral skills needed to adopt and maintain PA. ${ }^{36,38}$

\section{Clinical measures Demographic variables}

Participants reported their age, gender, race/ethnicity, current marital status, income, highest grade of school completed, and whether they were currently taking medications for hypertension or elevated cholesterol. ${ }^{43}$

\section{Body mass index}

Height to the nearest $1 / 10$ centimeter and weight to the nearest 1/10 kilogram were measured by trained staff and body mass index (BMI) was calculated.

\section{Lipids and lipoproteins}

Blood samples were drawn after an overnight fast and analyzed in a central laboratory for TC, HDL-C, LDL-C (calculated from the Friedewald equation ${ }^{44}$ ), and triglycerides. The ratio of TC to HDL-C was calculated for analyses.

\section{Blood pressure}

After participants sat quietly for 5 minutes, resting SBP and DBP was measured three times using a standard mercury sphygmomanometer. The average of the second and third measures was used for statistical analyses.

\section{Cardiorespiratory fitness}

Fitness was assessed by measuring maximal oxygen uptake ( $\mathrm{VO}_{2} \mathrm{max}, \mathrm{mL} / \mathrm{kg} / \mathrm{min}$ ) using a graded maximal exercise test on a treadmill at the baseline and 24-month visits. After participants warmed up with a brief walk at a $0 \%$ grade, the speed was increased until steady-state heart rate of $60 \%$ of age-predicted maximum or a rating of $11-13$ on the Borg scale ${ }^{45}$ of perceived exertion was maintained for 4 minutes. Then, treadmill grade was elevated $2 \%$ in 2-minute stages until the rate of perceived exertion (RPE) reached 17 or above, thereafter increasing the grade by $1 \%$ until the participant reached volitional fatigue or standard stopping criteria. ${ }^{46}$

\section{Statistical analyses}

The original study was powered to test outcomes for men and women separately. ${ }^{37,38}$ Therefore, all analyses were stratified by sex. All statistical analyses were performed using SAS (version 9.2; SAS Institute, Cary, NC). Repeated measures ANOVA procedures (using SAS PROC MIXED) were used to examine change over time in SBP, DBP, TC, HDL-C, LDL-C, TC to HDL-C ratio, and triglycerides. Because Group $\times$ Time interactions revealed no significant differences in change over time between study arms on any of the CVD risk factors examined, this term was removed from all models, and the effects of time, independent of arm, were examined. All models controlled for arm, race/ethnicity, education, age, sex, baseline BMI, and clinical site. The same set of models for each outcome variable was repeated, adding medication intake as a time-varying covariate (blood pressure medication [yes/no] for SBP and DBP models; and high cholesterol medication [yes/no] for TC, HDL-C, LDL-C, TC to HDL-C ratio, and triglycerides models). Finally, Time $\times$ Baseline risk factor status interactions (high versus normal, except HDL-C, which was classified as low versus normal) examined whether changes in CVD risk factors differed according to baseline risk factor status. "High" was defined as the following: SBP $\geq 140, \mathrm{DBP} \geq 90, \mathrm{TC} \geq 240$, TC to HDL-C ratio $\geq 5: 1$, LDL-C $\geq 160$, and triglycerides $\geq 200$, whereas "low" was defined as HDL-C $<40$ for men and $<50$ for women. Participants who reported being on blood pressure or high cholesterol medication at baseline were classified as "high" (or "low" for HDL-C) for the corresponding blood pressure and/or cholesterol analyses.

ANCOVA models (SAS PROC GLM) examined the relationship between changes in each of the secondary outcomes 
and changes in fitness, independent of arm assignment. Because changes in weight may be related to changes in CVD risk factors and thus potentially confound fitness-CVD risk factor relationship, we also examined the relationship between changes in the secondary outcomes and changes in weight. To test the independent effects of each, both variables (ie, changes in fitness and weight) were entered simultaneously into the model. A separate model, controlling for the same covariates above, was conducted for each of the CVD risk factors.

\section{Results}

Participants were 479 men and 395 women with a mean age of $51.2 \pm 9.7$ years for women and $50.7 \pm 9.6$ years for men (Table 1). There were no differences between intervention arms on key demographic variables for women or men. At baseline, $36 \%$ of women and $34 \%$ of men were classified as hypertensive (SBP $\geq 140 \mathrm{~mm} \mathrm{Hg}, \mathrm{DBP} \geq 90 \mathrm{~mm} \mathrm{Hg}$ or taking antihypertensive medication) and $21 \%$ of women and $26 \%$ of men had hyperlipidemia (LDL-C $\geq 160 \mathrm{mg} / \mathrm{dL}$ or taking lipid-lowering medication). There were no differences between groups on any CVD risk factors at baseline for either gender (Table 2).

\section{Changes in CVD risk factors: women}

Table 2 shows the adjusted means for each CVD risk factor at baseline and 24 months for women. Results showed a significant increase in SBP $(P=0.004)$. There were no significant changes in DBP $(P=0.83), \mathrm{TC}(P=0.45)$, HDL-C $(P=0.90)$, LDL-C $(P=0.42)$, the TC to HDL-C ratio $(P=0.90)$, or triglycerides $(P=0.99)$. Models adjusting for medication intake did not significantly change the results for any of the risk factors (data not shown).

Table 3 shows whether changes in CVD risk factors differed by baseline risk factor status. Significant Time $\times$ Baseline risk factor status interactions were found for all CVD risk factors $(P<0.0001$ for all). SBP significantly increased among participants with high SBP at baseline $(P=0.01)$ but not among those with normal blood pressure $(P=0.13)$. TC significantly decreased among participants with high TC at baseline $(P<0.0001)$, but significantly increased among participants with normal TC at baseline $(P=0.04)$. HDL-C significantly increased in participants with low HDL-C at baseline $(P=0.01)$, but did not change among those with normal baseline HDL-C $(P=0.05)$. There were significant decreases in LDL-C $(P<0.0001)$, the TC to HDL-C ratio $(P=0.01)$, and triglycerides $(P=0.001)$ among participants with high corresponding baseline levels, but not among participants with normal levels ( $P=0.07, P=0.08$, and $P=0.11$, respectively). Finally, although DBP was significantly different among those
Table I Baseline characteristics of men and women in the Activity Counseling Trial

\begin{tabular}{|c|c|c|c|c|}
\hline & \multicolumn{2}{|c|}{$\begin{array}{l}\text { Women } \\
(n=395)\end{array}$} & \multicolumn{2}{|c|}{$\begin{array}{l}\text { Men } \\
(n=479)\end{array}$} \\
\hline & $\mathbf{N}$ & $\begin{array}{l}\% \text { or } \\
\text { Mean } \pm \text { SD }\end{array}$ & $\mathbf{N}$ & $\begin{array}{l}\% \text { or } \\
\text { Mean } \pm \text { SD }\end{array}$ \\
\hline Age & 395 & $51.2 \pm 9.7$ & 479 & $50.7(9.6)$ \\
\hline \multicolumn{5}{|l|}{ Race } \\
\hline White & 253 & 64.4 & 344 & 72.6 \\
\hline Black & 121 & 30.8 & 96 & 20.3 \\
\hline Other & 19 & 4.8 & 34 & 7.2 \\
\hline \multicolumn{5}{|l|}{ Education } \\
\hline $\begin{array}{l}<\text { High school } \\
\text { graduate }\end{array}$ & 33 & 8.4 & 14 & 2.9 \\
\hline $\begin{array}{l}\text { High school } \\
\text { graduate }\end{array}$ & 61 & 15.4 & 30 & 6.3 \\
\hline Some college & 158 & 40.0 & 87 & 18.2 \\
\hline College graduate & 76 & 19.2 & 155 & 32.4 \\
\hline Postgraduate & 67 & 17.0 & 193 & 40.3 \\
\hline \multicolumn{5}{|l|}{$\begin{array}{l}\text { Income (USD, per } \\
\text { annum) }\end{array}$} \\
\hline$<\$ 30,000$ & 135 & 35.6 & 56 & 11.9 \\
\hline $\begin{array}{l}\$ 30,000 \text { to } \\
<\$ 50,000\end{array}$ & 91 & 24.0 & 61 & 13.0 \\
\hline $\begin{array}{l}\$ 50,000 \text { to } \\
<\$ 75,000\end{array}$ & 63 & 16.6 & 97 & 20.6 \\
\hline $\begin{array}{l}\$ 75,000 \text { to } \\
<\$ 100,000\end{array}$ & 40 & 10.6 & 85 & 18.1 \\
\hline$\$ 100,000+$ & 50 & 13.2 & 172 & 36.5 \\
\hline \multicolumn{5}{|l|}{ Employment status } \\
\hline Employed & 275 & 69.8 & 40913 & 85.4 \\
\hline Unemployed & 19 & 4.8 & 46 & 2.7 \\
\hline Retired & 43 & 10.9 & 11 & 9.6 \\
\hline Homemaker & 46 & 11.7 & $\mathrm{n} / \mathrm{a}$ & 2.3 \\
\hline Other & 11 & 2.8 & $\mathrm{n} / \mathrm{a}$ & $\mathrm{n} / \mathrm{a}$ \\
\hline \multicolumn{5}{|l|}{ Current smoker } \\
\hline Yes & 40 & 10.2 & 38 & 7.9 \\
\hline No & 353 & 89.8 & 441 & 92.1 \\
\hline BMI $\left(\mathrm{kg} / \mathrm{m}^{2}\right)$ & 389 & $30.4 \pm 7.2$ & 475 & $28.9 \pm 5.2$ \\
\hline $\mathrm{VO}_{2} \max (\mathrm{mL} / \mathrm{kg} / \mathrm{min})$ & 395 & $20.7 \pm 5.4$ & 479 & $28.8 \pm 6.5$ \\
\hline \multicolumn{5}{|l|}{ Hypertension } \\
\hline Yes & $|4|$ & 35.7 & 163 & 34.0 \\
\hline No & 254 & 64.3 & 316 & 66.0 \\
\hline \multicolumn{5}{|l|}{ Hyperlipidemia } \\
\hline Yes & 80 & 21.2 & 120 & 25.8 \\
\hline No & 297 & 78.8 & 345 & 74.2 \\
\hline
\end{tabular}

Abbreviations: BMI, body mass index; SD, standard deviation; n/a, not applicable; $\mathrm{VO}_{2}$ max, maximal oxygen uptake.

with high and normal baseline levels, neither group changed significantly over time.

\section{Changes in CVD risk factors: men}

Table 2 shows the adjusted means for each CVD risk factor examined at baseline and 24 months for men. Results showed a significant decrease in $\mathrm{DBP}(P=0.0002), \mathrm{TC}(P<0.0001)$, LDL-C $(P<0.0001)$, the TC to HDL-C ratio $(P=0.01)$, and 
Table 2 Cardiovascular disease risk factors at each assessment time for women and men

\begin{tabular}{|c|c|c|c|c|c|c|}
\hline & \multicolumn{3}{|l|}{ Women } & \multicolumn{3}{|l|}{ Men } \\
\hline & Mean (SE) & $\%$ change & $P$-value & Mean (SE) & $\%$ change & $P$-value \\
\hline \multicolumn{7}{|l|}{ SBP, $\mathrm{mm} \mathrm{Hg}$} \\
\hline Baseline & $117.2(1.8)$ & 1.6 & 0.004 & $122.6(1.1)$ & -0.16 & 0.70 \\
\hline 24 months & II9.1 (1.8) & & & I $22.4(\mathrm{I} . \mathrm{I})$ & & \\
\hline \multicolumn{7}{|l|}{$\mathrm{DBP}, \mathrm{mm} \mathrm{Hg}$} \\
\hline Baseline & $74.4(1.1)$ & 0.13 & 0.83 & $80.7(0.69)$ & -1.6 & 0.002 \\
\hline 24 months & $74.5(I . I)$ & & & $79.4(0.70)$ & & \\
\hline \multicolumn{7}{|l|}{$\mathrm{TC}, \mathrm{mg} / \mathrm{dL}$} \\
\hline Baseline & $194.9(5.0)$ & -0.62 & 0.45 & $204.3(3.2)$ & -4.4 & $<0.0001$ \\
\hline 24 months & $193.7(5.1)$ & & & $195.6(3.3)$ & & \\
\hline \multicolumn{7}{|l|}{ HDL-C, mg/dL } \\
\hline Baseline & $50.9(1.9)$ & 0.0 & 0.90 & $41.7(0.91)$ & 0.24 & 0.78 \\
\hline 24 months & $50.9(1.9)$ & & & $41.8(0.92)$ & & \\
\hline \multicolumn{7}{|l|}{ LDL-C, mg/dL } \\
\hline Baseline & $121.2(4.6)$ & -1.0 & 0.42 & I 32.5 (2.9) & -5.2 & $<0.0001$ \\
\hline 24 months & $120.0(4.6)$ & & & I $26.0(2.9)$ & & \\
\hline \multicolumn{7}{|l|}{ TC/HDL-C } \\
\hline Baseline & $4.2(0.17)$ & 0.0 & 0.90 & $5.2(0.14)$ & -4.0 & 0.005 \\
\hline 24 months & $4.2(0.18)$ & & & $5.0(0.14)$ & & \\
\hline \multicolumn{7}{|c|}{ Triglycerides, mg/dL } \\
\hline Baseline & $114.2(9.2)$ & 0.09 & 0.99 & $150.3(9.1)$ & -8.1 & 0.01 \\
\hline 24 months & I I4.I (9.3) & & & | 39.1 (9.2) & & \\
\hline
\end{tabular}

Note: All models controlled for group, race, education, age, sex, and clinical site.

Abbreviations: DBP, diastolic blood pressure; HDL-C, high-density lipoprotein cholesterol; LDL-C, low-density lipoprotein cholesterol; SBP, systolic blood pressure; $\mathrm{SE}$, standard error; TC, total cholesterol.

triglycerides $(P=0.01)$. There were no significant changes in SBP $(P=0.70)$ or HDL-C $(P=0.78)$. Models adjusting for medication intake did not significantly change the results for any of the risk factors (data not shown).

Table 3 shows whether changes in CVD risk factors differed by baseline risk factor status. Significant Time $\times$ Baseline risk factor status interactions were found for all CVD risk factors $(P<0.0001$ for all). There were significant decreases in DBP $(P<0.0001)$, TC $(P<0.0001)$, LDL-C $(P<0.0001)$, the TC to HDL-C ratio $(P<0.0001)$, and triglycerides $(P<0.0001)$ among participants with high corresponding baseline levels but not among participants with normal levels ( $P=0.08, P=0.09, P=0.64, P=0.22, P=0.62$, respectively $)$. HDL-C significantly increased in participants with low HDL-C at baseline $(P=0.04)$ but did not change among those with normal baseline HDL-C $(P=0.06)$. Finally, although SBP was significantly different among those with high and normal baseline levels, neither group significantly changed over time.

\section{Associations between changes in fitness, weight, and CVD risk factors: women}

There were a number of significant associations between changes in CVD risk factors and changes in fitness and weight in women participating in ACT (Table 4). An increase in fitness from baseline to 24 months was associated with a significant decrease in TC $(P=0.01)$ and triglycerides $(P=0.03)$ from baseline to 24 months. A decrease in weight from baseline to 24 months was associated with a decrease in SBP $(P=0.002)$, DBP $(P=0.0003)$, the TC to HDL-C ratio $(P=0.01)$, and triglycerides $(P=0.003)$, and an increase in HDL-C $(P<0.0001)$ from baseline to 24 months. When changes in fitness and changes in weight were entered simultaneously into the model, only one result changed: an increase in fitness was no longer associated with a decrease in triglycerides after controlling for change in weight $(P=0.17)$.

\section{Associations between changes in fitness, weight, and CVD risk factors: men}

There were a number of significant associations between changes in CVD risk factors and changes in fitness and weight in men participating in the ACT (Table 4). An increase in fitness from baseline to 24 months was associated with a significant decrease in the TC to HDL-C ratio $(P=0.004)$ and triglycerides $(P=0.003)$, and an increase in HDL-C $(P=0.003)$ from baseline to 24 months. There was also a borderline significant relationship in the expected direction for DBP $(P=0.06)$. A decrease in weight from baseline to 
Table 3 Cardiovascular disease risk factors for women and men at baseline and 24 months, by baseline risk factor level

\begin{tabular}{|c|c|c|c|c|c|c|c|c|}
\hline & \multicolumn{4}{|l|}{ Women } & \multicolumn{4}{|l|}{ Men } \\
\hline & \multirow{2}{*}{$\frac{\text { Baseline }}{\text { Mean (SE) }}$} & \multicolumn{3}{|l|}{24 months } & \multirow{2}{*}{$\frac{\text { Baseline }}{\text { Mean (SE) }}$} & \multicolumn{3}{|l|}{24 months } \\
\hline & & Mean (SE) & $\%$ change & $\begin{array}{l}P \text {-value } \\
\text { Interaction }\end{array}$ & & Mean (SE) & $\%$ change & $\begin{array}{l}\text { P-value } \\
\text { Interaction }\end{array}$ \\
\hline \multicolumn{9}{|c|}{$\mathrm{SBP}, \mathrm{mm} \mathrm{Hg}$} \\
\hline Normal & II3.9 (I.8) & II5.I (I.8) & I.I & $<0.000$ I & $119.3(1.0)$ & $119.0(1.1)$ & -0.25 & $<0.0001$ \\
\hline High & $|2| . \mid(1.9)$ & $124.3(2.0)^{\mathrm{a}}$ & 2.6 & & $13 \mid .4(1.3)$ & $|3| .7(\mid .4)$ & 0.23 & \\
\hline \multicolumn{9}{|c|}{ DBP, $\mathrm{mm} \mathrm{Hg}$} \\
\hline Normal & $72.6(I .1)$ & $72.5(I . I)$ & -0.14 & $<0.000$ I & $78.0(0.69)$ & $77.4(0.70)$ & -0.78 & $<0.0001$ \\
\hline High & $76.4(I . I)$ & $76.9(1.2)$ & 0.10 & & $86.0(0.83)$ & $83.5(0.86)^{\mathrm{a}}$ & -3.0 & \\
\hline \multicolumn{9}{|l|}{$\mathrm{TC}, \mathrm{mg} / \mathrm{dL}$} \\
\hline Normal & I86.2 (4.3) & $189.5(4.4)^{\mathrm{a}}$ & 1.8 & $<0.000 \mathrm{I}$ & 193.7 (2.9) & $190.8(3.0)$ & -1.5 & $<0.0001$ \\
\hline High & $240.7(5.4)$ & $223.5(5.6)^{\mathrm{a}}$ & -7.7 & & 245.5 (3.9) & $217.2(4.1)^{\mathrm{a}}$ & -13.0 & \\
\hline \multicolumn{9}{|c|}{ HDL-C, mg/dL } \\
\hline Normal & $60.0(1.5)$ & $58.5(1.6)$ & -2.6 & $<0.0001$ & $48.5(0.8 I)$ & $47.4(0.84)$ & -2.3 & $<0.0001$ \\
\hline Low & $4 I .0(1.5)$ & $43.0(1.6)^{\mathrm{a}}$ & 4.9 & & $35.0(0.8 I)$ & $36.0(0.83)^{\mathrm{a}}$ & 2.9 & \\
\hline \multicolumn{9}{|c|}{ LDL-C, mg/dL } \\
\hline Normal & I I 3.5 (4.0) & I I 6.3 (4.0) & 2.5 & $<0.000 \mathrm{I}$ & $120.2(2.6)$ & II $9.5(2.7)$ & 0.59 & $<0.0001$ \\
\hline High & $162.7(5.0)$ & $147.1(5.1)^{\mathrm{a}}$ & -10.6 & & $165.0(3.3)$ & $142.2(3.4)^{\mathrm{a}}$ & -16.0 & \\
\hline \multicolumn{9}{|l|}{ TC/HDL-C } \\
\hline Normal & $3.6(0.14)$ & $3.7(0.15)$ & 2.8 & $<0.0001$ & $4.0(0.12)$ & $4.1(0.13)$ & 2.5 & $<0.0001$ \\
\hline High & $5.5(0.16)$ & $5.2(0.17)^{a}$ & 5.8 & & $6.3(0.12)$ & $5.9(0.12)^{\mathrm{a}}$ & -6.8 & \\
\hline \multicolumn{9}{|c|}{ Triglycerides, mg/dL } \\
\hline Normal & $97.4(7.6)$ & $103.0(7.8)$ & 5.7 & $<0.000 \mathrm{I}$ & II 0.1 (7.4) & II $2.6(7.7)$ & 2.3 & $<0.0001$ \\
\hline High & $214.4(10.3)$ & $184.2(11.1)^{\mathrm{a}}$ & -16.4 & & $265.7(9.5)$ & $220.6(9.9)^{\mathrm{a}}$ & -20.4 & \\
\hline
\end{tabular}

Notes: a $P<0.05$; All models controlled for group, race, education, age, sex, and clinical site.

Abbreviations: DBP, diastolic blood pressure; HDL-C, high-density lipoprotein cholesterol; LDL-C, low-density lipoprotein cholesterol; SBP, systolic blood pressure; $\mathrm{SE}$, standard error; TC, total cholesterol.

24 months was associated with a decrease in $\operatorname{SBP}(P=0.003)$, DBP $(P<0.0001)$, TC $(P<0.0001)$, the TC to HDL-C ratio $(P<0.0001)$, and triglycerides $(P \leq 0.0001)$, and an increase in HDL-C $(P=0.008)$ from baseline to 24 months. There were no other significant relationships for any other CVD risk factors examined. When changes in fitness and weight were entered simultaneously into the model, results did not change for weight, with the exception of HDL-C, which was no longer related to decreases in weight $(P=0.09)$. Although HDL-C $(P=0.04)$ remained significant, changes in the TC to HDL-C ratio $(P=0.20)$ and triglycerides $(P=0.19)$ were no longer associated with changes in fitness. The borderline relationship of fitness to DBP also disappeared $(P=0.60)$.

\section{Discussion}

Intervention approaches that can be successfully disseminated and result in meaningful reductions in CVD risk factors are needed. This study evaluated the effects of three levels of a PA intervention delivered in primary care settings on CVD risk factors. Several risk factor improvements were achieved, irrespective of intervention assignment, for men and women with unfavorable baseline levels of CVD risk factors, but not for those with normal baseline levels.
The lack of significant differences between intervention arms over time should not be interpreted as unsuccessful intervention approaches. Although the advice arm was considered the "control arm", there really was not a true control arm in ACT. All participants (including those in the advice arm) received 2-4 minutes of PA counseling from a physician/health care provider in addition to written materials about PA from a health educator. Although physician advice about PA is recommended as part of standard practice, ${ }^{47}$ a majority of physicians are not counseling patients on PA. ${ }^{48}$ Furthermore, all participants completed extensive assessments throughout the course of the trial, including repeated maximal exercise tests, which could have influenced motivation to change behavior. ${ }^{49}$ Finally, many participants in ACT were recruited through physician-signed letters which could have also provided additional behavioral motivation in all arms.

Significant improvements in CVD risk factors were seen in both men and women who had high (or low for HDL-C) baseline levels of CVD risk factors, with the exception of SBP, which did not change in men or women, and DBP, which only improved in men. However, none of the CVD risk factors improved among participants with normal baseline 
Table 4 Relationship between changes in CVD risk factors and I) changes in fitness, 2) changes in weight, and 3) changes in fitness + weight

\begin{tabular}{|c|c|c|c|c|c|c|c|c|}
\hline & \multicolumn{4}{|l|}{ Women } & \multicolumn{4}{|l|}{ Men } \\
\hline & \multicolumn{2}{|l|}{ Model I } & \multicolumn{2}{|l|}{ Model II } & \multicolumn{2}{|l|}{ Model I } & \multicolumn{2}{|l|}{ Model II } \\
\hline & $\begin{array}{l}\text { Estimate } \\
\text { (SE) }\end{array}$ & $P$-value & $\begin{array}{l}\text { Estimate } \\
\text { (SE) }\end{array}$ & $P$-value & $\begin{array}{l}\text { Estimate } \\
\text { (SE) }\end{array}$ & $P$-value & $\begin{array}{l}\text { Estimate } \\
(\mathrm{SE})\end{array}$ & $P$-value \\
\hline \multicolumn{9}{|l|}{$\mathrm{SBP}, \mathrm{mm} \mathrm{Hg}$} \\
\hline$\Delta$ Fitness & $-0.12(0.22)$ & 0.60 & $0.10(0.23)$ & 0.67 & $-0.14(0.15)$ & 0.33 & $0.03(0.15)$ & 0.87 \\
\hline$\Delta$ Weight & $2.9(0.09)$ & 0.002 & $0.32(0.10)$ & 0.002 & $0.35(0.12)$ & 0.003 & $0.34(0.13)$ & 0.008 \\
\hline \multicolumn{9}{|l|}{$\mathrm{DBP}, \mathrm{mm} \mathrm{Hg}$} \\
\hline$\Delta$ Fitness & $-0.12(0.12)$ & 0.32 & $0.01(0.13)$ & 0.96 & $-0.17(0.09)$ & 0.06 & $-0.05(0.09)$ & 0.60 \\
\hline$\Delta$ Weight & $0.18(0.05)$ & 0.0003 & $0.20(0.06)$ & 0.0004 & $0.28(0.07)$ & $<0.000 \mathrm{I}$ & $0.26(0.08)$ & 0.0008 \\
\hline \multicolumn{9}{|l|}{$\mathrm{TC}, \mathrm{mg} / \mathrm{dL}$} \\
\hline$\Delta$ Fitness & $-1.22(0.47)$ & 0.01 & $-1.09(0.50)$ & 0.03 & $-0.72(0.42)$ & 0.08 & $-0.22(0.44)$ & 0.62 \\
\hline$\Delta$ Weight & $0.27(0.21)$ & 0.20 & $0.24(0.22)$ & 0.28 & $1.45(0.33)$ & $<0.000$ I & $\mathrm{I} .40(0.37)$ & 0.0002 \\
\hline \multicolumn{9}{|c|}{ HDL-C, mg/dL } \\
\hline$\Delta$ Fitness & $0.03(0.19)$ & 0.88 & $-0.22(0.19)$ & 0.25 & $0.31(0.10)$ & 0.003 & $0.24(0.11)$ & 0.04 \\
\hline$\Delta$ Weight & $-0.32(0.08)$ & $<0.0001$ & $-0.37(0.09)$ & $<0.0001$ & $-0.22(0.08)$ & 0.008 & $-0.16(0.09)$ & 0.09 \\
\hline \multicolumn{9}{|l|}{ LDL-C, mg/dL } \\
\hline$\Delta$ Fitness & $-0.8 \mathrm{I}(0.45)$ & 0.08 & $-0.54(0.48)$ & 0.26 & $-0.28(0.39)$ & 0.48 & $-0.11(0.42)$ & 0.80 \\
\hline$\Delta$ Weight & $0.36(0.20)$ & 0.08 & $0.42(0.22)$ & 0.05 & $0.50(0.32)$ & 0.11 & $0.5 \mathrm{I}(0.35)$ & 0.15 \\
\hline \multicolumn{9}{|l|}{ TC/HDL-C } \\
\hline$\Delta$ Fitness & $-0.03(0.02)$ & 0.13 & $-0.01(0.02)$ & 0.50 & $-0.05(0.02)$ & 0.004 & $-0.03(0.02)$ & 0.20 \\
\hline$\Delta$ Weight & $0.02(0.01)$ & 0.01 & $0.02(0.01)$ & 0.01 & $0.08(0.01)$ & 0.0001 & $0.07(0.02)$ & $<0.0001$ \\
\hline \multicolumn{9}{|c|}{ Triglycerides, mg/dL } \\
\hline$\Delta$ Fitness & $-2.23(1.04)$ & 0.03 & $-1.51(1.09)$ & 0.17 & $-3.69(1.22)$ & 0.003 & $-1.65(1.27)$ & 0.19 \\
\hline$\Delta$ Weight & $1.38(0.46)$ & 0.003 & $1.18(0.49)$ & 0.02 & $5.88(0.93)$ & $<0.0001$ & $5.19(1.05)$ & $<0.0001$ \\
\hline
\end{tabular}

Notes: All models controlled for group, race, education, age, sex, and clinical site. Model I tested the effects of $\Delta$ Fitness and $\Delta$ Weight separately. Model II entered $\Delta$ Fitness and $\Delta$ Weight in the model simultaneously, testing the independent effects of each.

Abbreviations: DBP, diastolic blood pressure; HDL-C, high-density lipoprotein cholesterol; LDL-C, low-density lipoprotein cholesterol; SBP, systolic blood pressure; $\mathrm{SE}$, standard error; TC, total cholesterol.

levels. These results are not surprising, as participants with normal risk factors had less room for improvement. The significant improvements in participants with unfavorable baseline levels of risk factors are notable, as these individuals have the greatest need for meaningful reductions in risk factors and thus should be targeted in behavioral interventions focusing on CVD risk reduction.

DBP significantly decreased in men with high DBP at baseline. Although modest at the individual level (decrease of $2.5 \mathrm{~mm} \mathrm{Hg}$ ), this change should be interpreted within a public health context. A $2 \mathrm{~mm} \mathrm{Hg}$ reduction in DBP applied across the population as a whole would reduce the prevalence of hypertension by $17 \%$, and reduce the incidence of coronary heart disease (CHD) by $6 \%$ and incidence of stroke by $15 \% .{ }^{50}$ The significant decreases in LDL-C, TC, triglycerides, and the TC to HDL-ratio, and the significant increase in HDL-C among men and women with high levels at baseline, are also encouraging. Adjusted levels of LDL-C decreased $\sim 11 \%$ in women and $\sim 16 \%$ in men, TC decreased $\sim 8 \%$ in women and $\sim 13 \%$ in men, triglycerides decreased $\sim 16 \%$ in women and $\sim 20 \%$ in men, and the TC to HDL-ratio decreased $\sim 5 \%$ in women and $\sim 7 \%$ in men, whereas HDL-C improved $\sim 5 \%$ in women and $\sim 3 \%$ in men. These changes are important and meaningful, as a $1 \%$ decrease in LDL-C is associated with a $1 \%$ reduction in the risk for $\mathrm{CHD},{ }^{51}$ whereas a $1 \%$ decrease in TC is associated with a $2 \%$ reduction in CHD risk. ${ }^{51}$ Improvements of this magnitude across the $21 \%$ of adults who have high LDL-C ${ }^{4}$ and the $29 \%$ who have hypertension $(\geq 140 / 90 \mathrm{~mm} \mathrm{Hg})^{5}$ would produce powerful public health benefit.

Results from other home-based and/or lifestyle PA intervention studies have found mixed results on CVD risk factors. For example, a study by King et $\mathrm{al}^{29}$ examining the effects of group- and home-based exercise programs on CVD risk factors found that although no effect was found at 1 year, there was a significant increase in HDL-C after 2 years among participants in two telephone-assisted homebased exercise training programs. However, there were no effects at either time point on TC, LDL-C, triglycerides, or blood pressure in this generally normotensive and nonhyerlipidemic sample of middle-aged adults. Dunn et $\mathrm{al}^{52}$ found significant decreases in SBP, DBP, TC, the TC to HDL-C 
ratio, and triglycerides, but not in LDL-C and HDL-C at 6 months among middle-aged participants in a lifestyle PA intervention group. However, SBP and DBP were the only risk factor reductions maintained at 24 months. ${ }^{26}$ Two other studies delivered in general practice settings by an exercise specialist $^{28}$ and a general practitioner and exercise specialist ${ }^{30}$ found significant within-group changes in CVD risk factors. However, differences between the intervention and control groups were not significant. Halbert et $\mathrm{al}^{28}$ found significant decreases in SBP and DBP in the intervention but not control group, whereas Elley et $\mathrm{al}^{30}$ found a decrease in TC, LDL-C, and triglycerides in both the intervention and control group, but no effects on blood pressure or HDL-C.

Changes in several CVD risk factors were associated with changes in fitness and weight. However, almost all of the significant relationships for fitness disappeared after controlling for weight change. The exceptions were for HDL-C (men) and TC (women), which remained independently associated with changes in fitness. An observational study by Sternfeld et $\mathrm{al}^{53}$ also found significant associations between changes in TC, HDL-C, LDL-C, and triglycerides and changes in fitness and weight over a 7 -year period. When examining the independent effects of fitness, similar to the present results for men, HDL-C was the only risk factor that remained significant. Results from these studies suggest that much of the association between changes in fitness and lipids is accounted for by changes in weight. ${ }^{53}$ It is unclear whether weight change confounds the relationship between changes in fitness and CVD risk factors or if it is part of the pathway by which fitness and weight work together to influence CVD risk factors. ${ }^{53}$ However, the independent effects of fitness on HDL-C, and perhaps on TC, suggest that confounding alone may not explain these complex relationships.

This study has a number of strengths including the objective measures of fitness, blood pressure, lipids, and lipoproteins. The large sample size also allowed gender-specific analyses. We also recognize our study limitations. The sample was predominantly highly educated and affluent, and over $70 \%$ of participants were White. Therefore, the study results may not generalize to other populations. Finally, changes in the dosage of blood pressure and cholesterol medications were not captured at the 24-month follow-up visit. Additional analyses excluding individuals on medication were conducted, and with a few exceptions, the results did not change. These findings suggest that changes in medication did not produce the improvements in CVD risk factors.

Interventions that can be implemented nationwide and that result in meaningful population-wide changes in CVD risk factors are needed. To overcome the challenges and barriers associated with behavioral interventions delivered by physicians in primary care settings, intervention protocols need to be parsimonious and efficient. Improvements in lipids from the ACT interventions could reduce the risk of CHD in people with already high levels of lipids by $16 \%-26 \%$ in men and $11 \%-16 \%$ in women. From a public health perspective, these results are promising, as asking physicians to briefly counsel patients on PA during each visit may be realistic. ${ }^{54}$ Although significant improvements in CVD risk factors were found only among those with at-risk levels, it is important to note that PA provides other cardiovascular benefits beyond improvements in risk factor markers (ie, blood pressure, lipids), as well as mental health benefits. An innovative initiative launched by the American College of Sports Medicine and the American Medical Association, called Exercise is Medicine ${ }^{\mathrm{TM}}$, is encouraging primary care physicians, as well as other health professionals, to include regular PA in treatment plans for patients. ${ }^{55}$ This initiative recognizes the importance of regular PA and calls on health care providers to treat PA as a "vital sign", which will result in the assessment and recording of PA at every clinic visit. The results from the present study provide support for the potential significance and success of such endeavors, particularly among individuals who may be in most need of changes.

\section{Acknowledgments}

ACT was supported the National Heart, Lung, and Blood Institute through contracts: N01-HC-45135, N01-HC-45136, N01-HC-45137, and N01-HC-45138. Support for this publication is also provided by the Robert Wood Johnson Foundation's Pioneer Portfolio, which supports innovative ideas that may lead to breakthroughs in the future of health and health care. The Pioneer Portfolio funding was administered through a Positive Health grant to the Positive Psychology Center of the University of Pennsylvania, Martin Seligman, director.

The investigators express their appreciation to ACTparticipating physicians and other health professionals, participating patients, and the Data and Safety Monitoring Board, whose members were Albert Oberman (Chair), Rod Dishman, Patricia Dubbert, Elisa Lee, I-Min Lee, and Russell Pate. The following were ACT investigators at the institutions designated at the time of completion of the trial. Clinical Centers: Cooper Institute for Aerobics Research/University of Texas Southwestern Medical Center, Steven Blair (Principal Investigator), Andrea Dunn, Larry Gibbons, Benjamin Levine (Co-Principal Investigator), Bess Marcus (Brown University), James Sallis (San Diego State University), and Peter Snell (UT SW Medical Center); The Stanford University School 
of Medicine, Abby King (Principal Investigator), Cheryl Albright, William Haskell, Lisa Palmer, Leslie Pruitt, and Wayne Phillips; University of Tennessee, Memphis, Mary O'Toole (Principal Investigator), William B. Applegate Consultant), Joyce Banton, Mace Coday, Karen C Johnson, Robert C Klesges (University of Memphis), Stephen T Miller, and J Lee Taylor. Coordinating Center: Wake Forest University School of Medicine, Timothy Morgan (Principal Investigator), Roger Anderson, Stuart Cohen, Mark Espeland, Walter Ettinger, Elizabeth Mayer-Davis, Michael Miller, Jack Rejeski (Wake Forest University), Paul Ribisl (Wake Forest University), Mary Ann Sevick, and Mara Vitolins. Central Laboratory: Penn Medical Laboratories, David Robbins. Project Office: National Heart, Lung, and Blood Institute, Denise Simons-Morton (Project Officer), P Scott Allender, Eva Obarzanek, Joanna Shih, and Carolyn Voorhees.

\section{Disclosure}

The authors report no conflicts of interest in this work.

\section{References}

1. Xu J, Kochanek KD, Tejada-Vera B. Deaths: preliminary data for 2007. National Vital Statistics Report. 2009;58(1). Hyattsville, MD: National Center for Health Statistics; 2009. Available from: http://www.cdc.gov/ nchs/data/nvsr/nvsr58/nvsr58_01.pdf. Accessed Dec 102010.

2. Stamler J, Stamler R, Neaton JD. Blood pressure, systolic and diastolic, and cardiovascular risks. US population data. Arch Intern Med. 1993; 153(5):598-615.

3. Stamler J, Wentworth D, Neaton JD. Is relationship between serum cholesterol and risk of premature death from coronary heart disease continuous and graded? Findings in 356,222 primary screenees of the Multiple Risk Factor Intervention Trial (MRFIT). JAMA. 1986;256(20):2823-2828.

4. Kuklina EV, Yoon PW, Keenan NL. Trends in high levels of low-density lipoprotein cholesterol in the United States, 1999-2006. JAMA. 2009; 302(19):2104-2110.

5. Cutler JA, Sorlie PD, Wolz M, Thom T, Fields LE, Roccella EJ. Trends in hypertension prevalence, awareness, treatment, and control rates in United States adults between 1988-1994 and 1999-2004. Hypertension. 2008;52(5):818-827.

6. Whelton SP, Chin A, Xin X, He J. Effect of aerobic exercise on blood pressure: a meta-analysis of randomized, controlled trials. Ann Intern Med. 2002;136(7):493-503.

7. Monda KL, Ballantyne CM, North KE. Longitudinal impact of physical activity on lipid profiles in middle-aged adults: the Atherosclerosis Risk in Communities Study. J Lipid Res. 2009;50(8):1685-1691.

8. Lloyd-Jones D, Adams RJ, Brown TM, et al. Heart disease and stroke statistics - 2010 update. A report from the American Heart Association. Circulation. 2010;121(7):e46-e215.

9. Andersen RE, Wadden TA, Bartlett SJ, Zemel B, Verde TJ, Franckowiak SC. Effects of lifestyle activity vs structured aerobic exercise in obese women: a randomized trial. JAMA. 1999;281(4):335-340.

10. Appel LJ, Champagne CM, Harsha DW, et al. Effects of comprehensive lifestyle modification on blood pressure control: main results of the PREMIER clinical trial. JAMA. 2003;289(16):2083-2093.

11. Ratner R, Goldberg R, Haffner S, et al. Impact of intensive lifestyle and metformin therapy on cardiovascular disease risk factors in the diabetes prevention program. Diabetes Care. 2005;28(4):888-894.
12. Lindstrom J, Louheranta A, Mannelin M, et al. The Finnish Diabetes Prevention Study (DPS): Lifestyle intervention and 3-year results on diet and physical activity. Diabetes Care. 2003;26(12):3230-3236.

13. Elmer PJ, Obarzanek E, Vollmer WM, et al. Effects of comprehensive lifestyle modification on diet, weight, physical fitness, and blood pressure control: 18-month results of a randomized trial. Ann Intern Med. 2006;144(7):485-495.

14. Naito M, Nakayama T, Okamura T, et al. Effect of a 4-year workplacebased physical activity intervention program on the blood lipid profiles of participating employees: the high-risk and population strategy for occupational health promotion (HIPOP-OHP) study. Atherosclerosis. 2008;197(2):784-790.

15. Stevens VJ, Obarzanek E, Cook NR, et al. Long-term weight loss and changes in blood pressure: results of the Trials of Hypertension Prevention, phase II. Ann Intern Med. 2001;134(1):1-11.

16. Stevens VJ, Corrigan SA, Obarzanek E, et al. Weight loss intervention in phase 1 of the Trials of Hypertension Prevention. The TOHP Collaborative Research Group. Arch Intern Med. 1993;153(7):849-858.

17. Miller ER 3rd, Erlinger TP, Young DR, et al. Results of the Diet, Exercise, and Weight Loss Intervention Trial (DEW-IT). Hypertension. 2002;40(5):612-618.

18. Whelton PK, Appel LJ, Espeland MA, et al. Sodium reduction and weight loss in the treatment of hypertension in older persons: a randomized controlled trial of nonpharmacologic interventions in the elderly (TONE). TONE Collaborative Research Group. JAMA. 1998; 279(11):839-846.

19. Simkin-Silverman L, Wing RR, Hansen DH, et al. Prevention of cardiovascular risk factor elevations in healthy premenopausal women. Prev Med. 1995;24(5):509-517.

20. Stefanick ML, Mackey S, Sheehan M, Ellsworth N, Haskell WL, Wood PD. Effects of diet and exercise in men and postmenopausal women with low levels of HDL cholesterol and high levels of LDL cholesterol. N Engl J Med. 1998;339(1):12-20.

21. Steptoe A, Doherty S, Rink E, Kerry S, Kendrick T, Hilton S. Behavioural counselling in general practice for the promotion of healthy behaviour among adults at increased risk of coronary heart disease: randomised trial. BMJ. 1999;319(7215):943-947; discussion 947-948.

22. Kastarinen MJ, Puska PM, Korhonen MH, et al. Non-pharmacological treatment of hypertension in primary health care: a 2-year open randomized controlled trial of lifestyle intervention against hypertension in eastern Finland. J Hypertens. 2002;20(12):2505-2512.

23. Effectiveness of health checks conducted by nurses in primary care: results of the OXCHECK study after one year. Imperial Cancer Research Fund OXCHECK Study Group. BMJ. 1994;308(6924):308-312.

24. Salkeld G, Phongsavan P, Oldenburg B, et al. The cost-effectiveness of a cardiovascular risk reduction program in general practice. Health Policy. 1997;41(2):105-119.

25. Effectiveness of health checks conducted by nurses in primary care: final results of the OXCHECK study. Imperial Cancer Research Fund OXCHECK Study Group. BMJ. 1995;310(6987):1099-1104.

26. Dunn AL, Marcus BH, Kampert JB, Garcia ME, Kohl HW, Blair SN. Comparison of lifestyle and structured interventions to increase physical activity and cardiorespiratory fitness: a randomized trial. JAMA. 1999;281(4):327-334.

27. Tudor-Locke C, Bell RC, Myers AM, et al. Controlled outcome evaluation of the First Step Program: a daily physical activity intervention for individuals with type II diabetes. Int $J$ Obes Relat Metab Disord. 2004;28(1):113-119.

28. Halbert JA, Silagy CA, Finucane PM, Withers RT, Hamdorf PA. Physical activity and cardiovascular risk factors: effect of advice from an exercise specialist in Australian general practice. Med J Aust. 2000;173(2):84-87.

29. King AC, Haskell WL, Young DR, Oka RK, Stefanick ML. Longterm effects of varying intensities and formats of physical activity on participation rates, fitness, and lipoproteins in men and women aged 50 to 65 years. Circulation. 1995;91(10):2596-2604. 
30. Elley CR, Kerse N, Arroll B, Robinson E. Effectiveness of counselling patients on physical activity in general practice: cluster randomised controlled trial. BMJ. 2003;326(7393):793.

31. Dickinson HO, Mason JM, Nicolson DJ, et al. Lifestyle interventions to reduce raised blood pressure: a systematic review of randomized controlled trials. J Hypertens. 2006;24(2):215-233.

32. Kelley GA, Kelley KS. Aerobic exercise and lipids and lipoproteins in men: a meta-analysis of randomized controlled trials. J Mens Health Gend. 2006;3(1):61-70.

33. Kelley GA, Kelley KS, Tran ZV. Aerobic exercise and lipids and lipoproteins in women: a meta-analysis of randomized controlled trials. J Womens Health (Larchmt). 2004;13(10):1148-1164.

34. National Center for Health Statistics. Health, United States, 2009. Hyattsville, MD: National Center for Health Statistics; 2009.

35. Fleming P, Godwin M. Lifestyle interventions in primary care: systematic review of randomized controlled trials. Can Fam Physician. 2008;54(12):1706-1713.

36. King AC, Sallis JF, Dunn AL, et al. Overview of the Activity Counseling Trial (ACT) intervention for promoting physical activity in primary health care settings. Activity Counseling Trial Research Group. Med Sci Sports Exerc. 1998;30(7):1086-1096.

37. Blair SN, Applegate WB, Dunn AL, et al. Activity Counseling Trial (ACT): rationale, design, and methods. Activity Counseling Trial Research Group. Med Sci Sports Exerc. 1998;30(7):1097-1106.

38. The Writing Group for the Activity Counseling Trial Research Group. Effects of physical activity counseling in primary care: the Activity Counseling Trial: a randomized controlled trial. JAMA. 2001;286(6):677-687.

39. Bandura A. Social Foundations of Thought and Action: a Social Cognitive Theory. Englewood Cliffs, NJ: Prentice Hall; 1986.

40. Prochaska JO, DiClemente CC, Norcross JC. In search of how people change. Applications to addictive behaviors. Am Psychol. 1992;47(9):1102-1114.

41. Pate RR, Pratt M, Blair SN, et al. Physical activity and public health. A recommendation from the Centers for Disease Control and Prevention and the American College of Sports Medicine. JAMA. 1995;273(5):402-407.

42. American College of Sports Medicine position stand. The recommended quantity and quality of exercise for developing and maintaining cardiorespiratory and muscular fitness in healthy adults. Med Sci Sports Exerc. 1990;22(2):265-274.
43. Simons-Morton DG, Hogan P, Dunn AL, et al. Characteristics of inactive primary care patients: baseline data from the activity counseling trial. For the Activity Counseling Trial Research Group. Prev Med. 2000;31(5):513-521.

44. Friedewald WT, Levy RI, Fredrickson DS. Estimation of the concentration of low-density lipoprotein cholesterol in plasma, without use of the preparative ultracentrifuge. Clin Chem. 1972;18(6):499-502.

45. Borg GA. Psychophysical bases of perceived exertion. Med Sci Sports Exerc. 1982;14(5):377-381.

46. American College of Sport Medicine. Guidelines for Exercise Testing and Prescription. 5th ed. Baltimore, MD: Williams \& Wilkins; 1995.

47. Jacobson DM, Strohecker L, Compton MT, Katz DL. Physical activity counseling in the adult primary care setting: position statement of the American College of Preventive Medicine. Am J Prev Med. 2005;29(2):158-162.

48. Russell NK, Roter DL. Health promotion counseling of chronic-disease patients during primary care visits. Am J Public Health. 1993; 83(7):979-982.

49. Van Sluijs EM, van Poppel MN, Twisk JW, van Mechelen W. Physical activity measurements affected participants' behavior in a randomized controlled trial. J Clin Epidemiol. 2006;59(4):404-411.

50. Cook NR, Cohen J, Hebert PR, Taylor JO, Hennekens CH. Implications of small reductions in diastolic blood pressure for primary prevention. Arch Intern Med. 1995;155(7):701-709.

51. National Institutes of Health. Third report of the National Cholesterol Education Program Expert Panel on Detection, Evaluation, and Treatment of High Blood Cholesterol in Adults (Adult Treatment Panel III), Final Report. Bethesda, MD: National Institutes of Health, National Heart, Lung and Blood Institute; 2002.

52. Dunn AL, Marcus BH, Kampert JB, Garcia ME, Kohl HW 3rd, Blair SN. Reduction in cardiovascular disease risk factors: 6-month results from Project Active. Prev Med. 1997;26(6):883-892.

53. Sternfeld B, Sidney S, Jacobs DR Jr, Sadler MC, Haskell WL, Schreiner PJ. Seven-year changes in physical fitness, physical activity, and lipid profile in the CARDIA study. Coronary Artery Risk Development in Young Adults. Ann Epidemiol. 1999;9(1):25-33.

54. King AC, Guralnik JM. Maximizing the potential of an aging population. JAMA. 2010;304(17):1944-1945.

55. American College of Sports Medicine. Exercise is Medicine. Indianapolis, IN: American College of Sports Medicine; 2008.
International Journal of General Medicine

\section{Publish your work in this journal}

The International Journal of General Medicine is an international, peer-reviewed open-access journal that focuses on general and internal medicine, pathogenesis, epidemiology, diagnosis, monitoring and treatment protocols. The journal is characterized by the rapid reporting of reviews, original research and clinical studies across all disease areas.

\section{Dovepress}

A key focus is the elucidation of disease processes and management protocols resulting in improved outcomes for the patient.The manuscript management system is completely online and includes a very quick and fair peer-review system. Visit http://www.dovepress.com/ testimonials.php to read real quotes from published authors. 